\title{
A REPRESENTAÇÃO DA IDENTIDADE DO PROFESSOR NA DISCURSIVIZAÇÃO DA REVISTA NOVA ESCOLA
}

\author{
THE REPRESENTATION OF THE IDENTIFY OF THE TEACHER IN \\ SPEECHLIZATION MAGAZINE'S NEW SCHOOL
}

\author{
Taciana Virgínia Ramalho PEREIRA (PG-Fafijan) \\ Fabiana Fernanda STEIGENBERGER (Fafijan/UFSCAR)
}

\begin{abstract}
Resumo: A linguagem não deve ser vista apenas como uma simbolização para gerar uma comunicação, ela é experiência cotidiana dos falantes situando-os no tempo e no espaço. Dessa forma, a Análise do Discurso busca estudar o homem na sua história para mostrar quais efeitos de sentidos podem ser produzidos no discurso. Embasada nessa linha teórica, a presente pesquisa se propõe a analisar as práticas linguageiras da Revista Nova Escola para averiguar o tipo de professor que o periódico endossa como bom profissional. Essa preocupação nos leva a analisar no fio discursivo as formas de representação da identidade do sujeito professor. E, consequentemente, o ethos construído para o docente. Para tanto, elegemos como corpus dois artigos de opinião publicados na coluna Pense Nisso do periódico aqui estudado.
\end{abstract}

Palavras-chave: Análise do Discurso. Bom professor. Ethos. Identidade.

\begin{abstract}
The language shouldn't be viewed simply as a symbolization to generate a communication, it is an daily experience of the speakers by locating it in time and space. By the way, the discourse analysis seeks to study man in his story to show what meaning effects can be produced in discourse. Based on this theoretical perspective, this present research study and analyse the language practices of New School Magazine to find out what kind of teacher who endorses the journal as a good professional. This preoccupation leads us to analyse the discursive thread forms of representation of the identity of the subject teacher. And consequently, the ethos built for the faculty. To this end, we choose as corpus two opinion articles published in the journal Think About It of the column studied here.
\end{abstract}

Keywords: Discourse Analysis. Good teacher. Ethos. Identity.

\section{Palavras Iniciais}

A Revista Nova Escola, criada em março de 1986, é uma publicação da Editora Abril com ampla circulação no segmento específico do magistério. Segundo a mídia nacional, essa publicação é considerada a revista mais difundida e popular entre os docentes da Educação Infantil e do Ensino Fundamental. Durante os cinco primeiros anos de edição, era vendida a preço de custo nas bancas e para as escolas públicas eram destinados exemplares gratuitos mensalmente. Essa situação colaborou para o elevado número de tiragens e viabilizou sua grande aceitação ao conquistar esse público específico. O periódico apresenta diferentes gêneros textuais: ensaios, entrevistas, artigos, reportagens, entre outros, os quais divulgam a reflexão e a propagação de concepções sobre ensino e aprendizagem, práticas bem sucedidas 
de sala de aula, metodologias de ensino e outros temas relacionados à práxis docente.

Esse veículo midiático presente no interior das instituições educacionais mobiliza no fazer enunciativo um discurso que colabora para construir a identidade docente. O discurso aí propagado impõe valores para estereotipar o professor e construir a imagem do "bom" profissional da docência. A materialização dessa imagem nas páginas da publicação tornou-se referência para os profissionais da área.

O presente artigo se propõe analisar as práticas linguageiras da Revista Nova Escola para averiguar o tipo de professor que o periódico endossa como bom profissional. Essa preocupação nos leva a analisar na prática discursiva as formas de representação da identidade do sujeito professor. E, consequentemente, o ethos construído para o docente por meio da propagação de uma doxa referente ao que é ser um bom professor. Para tanto, selecionamos artigos de opinião publicados em uma coluna específica da revista denominada Pense Nisso. A coluna integra essa publicação desde 2006, a princípio encontrava-se no meio do periódico, mas no momento está na última página. Seu articulista é o professor Luís Carlos de Menezes, doutor em física e professor sênior da Universidade de São Paulo (USP). As reflexões teóricas aqui realizadas embasam-se nos conceitos da Análise do Discurso de linha francesa. E recorre aos estudos de Amossy referentes ao ethos discursivo.

\section{Referencial Teórico}

Existem muitas maneiras de se estudar a linguagem: como sistema de signos e regras ou como normas tradicionais. É pensando nisso que os estudiosos começaram a se interessar pela linguagem de forma mais peculiar dando origem à Análise do Discurso Francesa. Apesar da língua e da gramática interessar á Análise do Discurso, sua maior preocupação concerne ao homem na história, e a partir dessa perspectiva considera a exterioridade da linguagem, o discurso como sócio-histórico e não a língua-fechada.

A Análise do Discurso (AD) teve início na França, nos anos 60, porém, já se apresentava de forma não sistemática em diferentes épocas e perspectivas ao trabalhar com a análise estrutural dos textos. No século XX, essa área do conhecimento herdou três regiões do saber: a psicanálise, a linguística e o marxismo. A partir daí, passa a interrogar a linguística pela historicidade, devido a sua ausência nesse campo do conhecimento; questiona o materialismo ao perguntar pelo simbólico; e se demarca da psicanálise pelo modo como trabalha a ideologia, como materialmente relacionada ao inconsciente sem ser absorvida por ele. A AD produz um novo objeto que afeta essas formas de conhecimento em seu conjunto: o discurso. Renova-se ao se importar com valores ideológicos e sociais: interlocutores, situação, contexto histórico-social fazem parte do seu processo de significação.

No funcionamento da linguagem há um processo de constituição entre sujeitos e língua. As relações de linguagem são relações de sujeitos e de sentidos e seus efeitos são múltiplos e variados. Daí a definição de discurso: o discurso é efeito de sentidos entre locutores. Deve-se levar em conta que a língua é condição de possibilidade do discurso e que a linguagem é linguagem porque faz sentido na história.

A Análise do Discurso visa à compreensão de como um objeto simbólico produz sentidos, qual sua significância ao sujeito. Esse entendimento explica como o texto organiza os gestos de interpretação que relacionam sujeito e sentido.

Cada material de análise exige que seu analista, de acordo com a questão que formula, mobilize conceitos que outro analista não mobilizaria, face as suas 
(outras) questões. Uma análise não é igual á outra porque mobiliza conceitos diferentes e isso tem resultados cruciais na descrição dos materiais. Um mesmo analista, aliás, formulando uma questão diferente, também poderia mobilizar conceitos diversos, fazendo distintos recortes conceituais. (ORLANDI, 1996, p.27).

De acordo com a citação da autora acima, um mesmo analista pode encontrar diversos efeitos de sentidos em um periódico. Para compreender os efeitos de sentido que um texto pode alcançar deve-se considerar as condições de produção que incluem o contexto sóciohistórico e ideológico. Para isso, é necessário acionar a memória discursiva tratada como interdiscurso, ou seja, tudo aquilo que já foi dito tem um efeito de sentido, o dizer não é propriedade particular, as palavras não são só nossas. Elas significam pela história e pela língua. Orlandi (1996) ressalta que as palavras falam com outras palavras. O fato de que há um já-dito que sustenta a possibilidade mesma de todo dizer é fundamental para se compreender o funcionamento do discurso, a sua relação com os sujeitos e com a ideologia. Há uma relação entre o já-dito e o que está dizendo que é o que existe entre o interdiscurso e o intradiscurso, ou entre a constituição do sentido e sua formulação. Courtine (1984) explicita essa diferença considerando "a constituição - o que estamos chamando de interdiscurso representada como um eixo vertical onde teríamos todos os dizeres já ditos - e esquecidos em uma estratificação de enunciados que, em seu conjunto, representa o dizível. E teríamos o eixo horizontal - intradiscurso - que seria o eixo da formulação, isto é, aquilo que estamos dizendo naquele momento dado, em condições dadas."

A constituição determina a formulação, pois só podemos dizer (formular) se nos colocamos na perspectiva do dizível (interdiscurso, memória). Todo dizer, na realidade, se encontra na confluência de dois eixos: o da memória (constituição) e o da atualidade (formulação). E é desse jogo que surgem seus sentidos.

O interdiscurso é da ordem do saber discursivo, memória afetada pelo esquecimento ao longo do dizer. Segundo Pêcheux:

Podemos distinguir duas formas de esquecimento no discurso. $\mathrm{O}$ esquecimento número dois, onde ao querermos pronunciar uma palavra ou expressão, acabamos por pronunciar outras do mesmo significado. Ele produz em nós a impressão da realidade do pensamento, por meio da qual achamos que aquelas palavras só podem ser ditas daquela forma. No esquecimento número um, temos a ilusão de ser a origem do que dizemos. $(1975$, p. 25).

As ilusões não são defeitos, constituem uma necessidade para que a linguagem funcione nos sujeitos e na produção de sentidos. Os sujeitos esquecem o que já foi dito, para ao se identificarem com o que dizem se constituírem em sujeitos. É assim que suas palavras adquirem sentido, que eles se significam retomando palavras já existentes como se elas se originassem neles. Dessa forma, os sentidos e os sujeitos estão sempre em movimento, significando sempre de muitas e variadas maneiras.

Ao produzirem sentidos discursivamente, os sujeitos atrelam-se às formações ideológicas que incluem uma ou várias formações discursivas. Segundo Pêcheux:

O conceito de formação discursiva pode ser compreendido como aquilo que, numa formação ideológica dada, isto é, a partir de uma posição dada numa conjuntura dada, determinada pelo estado da luta de classes, determina o que 


\section{INTERFACES DA EDUCAÇÃO}

pode e deve ser dito (articulado sob a forma de uma arenga, de um sermão, de um panfleto, de uma exposição, de um programa, etc. (1997, p.160)

Tendo como base essa acepção, torna-se necessário ressaltarmos que toda palavra é sempre parte de um discurso. E todo discurso se delineia na relação com outros: dizeres presentes e dizeres que se alojam na memória. As formações discursivas podem ser vistas como regionalizações do interdiscurso, configurações específicas dos discursos em suas relações.

O discurso se explicita em suas regularidades pela sua referência a uma ou outra formação discursiva que ganha sentido porque deriva de um jogo definido pela formação ideológica dominante naquela conjuntura. $\mathrm{O}$ funcionamento discursivo está ligado às formações imaginárias, ou seja, aos papéis que o sujeito assume ao enunciar, a que Pêcheux (1990) denomina "jogo de imagens", por envolver as representações que os interactantes fazem de seu lugar enunciativo e do lugar do referente em seus discursos.

No processo discursivo os interlocutores são representados por lugares determinados e organizados em uma formação social. Portanto, há "uma série de formações imaginárias que designam o lugar que A e B se atribuem cada um a si e ao outro, a imagem que eles se fazem de seu próprio lugar e do lugar do outro" (PÊCHEUX, 1990, p. 82). Assim, as práticas linguageiras pressupõem a existência de formações imaginárias, as quais foram descritas por Pêcheux com base nos jogos de imagens e podem ser compreendidas a partir das seguintes indagações: quem sou eu para lhe falar assim? Quem é ele para que eu lhe fale assim? Quem sou eu para que ele me fale assim? Quem é ele para que me fale assim?

O sujeito, dessa forma, não é um simples emissor, mas alguém que fala a partir de uma posição social, situada em relação a outro sujeito colocado também em uma dessas posições imaginárias. Com isso, se configura de forma incompleta, não sendo fixo e acabado, sempre idêntico a si mesmo, mas se constitui com e pelas experiências históricas. Nessa perspectiva, ao pensarmos o sujeito, devemos ter em mente as relações que os sujeitos mantêm consigo próprios, com os outros e com as verdades sócio-históricas. Tais relações subjazem à formação da identidade e possibilitam desvelar a imagem que o sujeito enunciador constrói para o bom professor no veículo midiático a Revista Nova Escola.

A função da imagem de si e do outro construída no discurso se manifesta nessa perspectiva interacional. Amossy (2005) acredita que "dizer que os participantes interagem é supor que a imagem de si construída no e pelo discurso participa da influência que exercem um sobre o outro". Para melhor compreensão, recorremos ao conceito de ethos, tal como é apresentado por Amossy. Segundo essa autora, o ethos está ligado ao locutor como tal: é como origem da enunciação que ele se vê investido de certos caracteres que, em contrapartida, tornam essa enunciação aceitável ou recusável. Analisar o locutor no discurso consiste não em ver o que ele diz de si mesmo, mas em conhecer a aparência que lhe conferem as modalidades de sua fala.

$\mathrm{Na}$ verdade, o enunciador deve se conferir e conferir a seu destinatário, certo status para legitimar seu dizer: ele se outorga no discurso uma posição institucional e marca sua relação com um saber. A maneira de dizer autoriza a construção de uma verdadeira imagem de si e, na medida em que o locutário se vê obrigado a depreendê-la a partir de diversos índices discursivos, ela contribui para o estabelecimento de uma inter-relação entre o locutor e seu parceiro.

Além da persuasão por argumentos, a noção de ethos permite refletir sobre o processo mais geral da adesão de sujeitos a certa posição discursiva. Esse conceito teórico se manifesta como voz e como corpo enunciante, historicamente especificado e inscrito em uma situação, 
que sua enunciação ao mesmo tempo pressupõe e valida progressivamente. O ethos está ligado à enunciação, se desdobra no registro do mostrado e, eventualmente, no do dito. $\mathrm{O}$ público constrói representações do enunciador antes mesmo que ele fale. Mesmo que o coenunciador não saiba nada sobre o caráter do enunciador, o simples fato de que um texto pertence a um gênero de discurso ou a certo posicionamento ideológico induz expectativas quanto à elaboração prévia do ethos.

Durante a enunciação o sujeito discursivo recorre a um conjunto de representações sociais valorizadas ou desvalorizadas, de estereótipos que contribuem para formar uma identidade compatível com o imaginário coletivo do seu co-enunciador e por seu próprio enunciado procura legitimar sua maneira de dizer.

O enunciador não é estável, deve ser considerado em um quadro interativo, em uma instituição discursiva inscrita em uma configuração cultural e que implica papéis, lugares e modos de enunciação legítimos, um suporte material e um modo de circulação para o enunciado. Sabemos, portanto, que ethos é uma imagem de si construída no discurso, por meio da qual procura-se influenciar opiniões e atitudes. Na discursivização da Revista Nova Escola, objeto do presente estudo, observa-se que o enunciador ao construir seu ethos, também busca a elaboração de um ethos para o docente, na tentativa de lhe indicar estereótipos e uma doxa com valores para a formação do conceito do bom professor, ou seja, aquele que segundo o periódico seria um bom profissional ao desenvolver a atividade da docência. Ao analisarmos essa prática discursiva, é possível ainda, verificarmos as formas de representação da identidade do sujeito professor, desencadeada a partir da constituição do ethos do bom docente.

Quando falamos de identidade a entendemos como um conceito em movimento, em constante mutação, com toda significação, sendo vista como incompleta, inacabada, fenômeno cuja constituição sempre comporta algum deslizamento. Woodward (2005) esclarece que a identidade depende de algo fora de si para existir. Ela é relacional, isto é, depende de outra identidade, de uma identidade que ela não é, que difere de si, mas que fornece as condições para que a mesma possa existir.

No lugar de identidade, alguns estudiosos preferem o termo identificação, por não remeter ao mesmo, ao idêntico. Hall esclarece que a identificação é:

(...) um processo de articulação, uma suturação, uma sobredeterminação, e não uma subsunção. Há sempre 'demasiado' ou 'muito pouco' - uma sobredeterminação ou uma falta, mas nunca um ajuste completo, uma totalidade. Como todas as práticas de significação, ela está sujeita ao 'jogo' da différance. Ela obedece à lógica do mais-que-um. E uma vez que, como num processo, a identificação opera por meio da différance, ela envolve um trabalho discursivo, o fechamento e a marcação de fronteiras simbólicas, a produção de 'efeitos de fronteiras'. Para consolidar o processo, ela requer aquilo que é deixado de fora - o exterior que a constitui. (2005, p. 106)

A concepção de identidade, para esta pesquisa, compreende esse processo descrito pela identificação, pois não tem como referente um eu que permanece sempre o "mesmo" ao longo do tempo. Nessa perspectiva, concebemos a identidade enquanto um "tornar-se" e não como um "ser". Elas não são nunca unificadas, mas fragmentadas, construídas discursivamente de forma múltipla, evidenciando práticas e posições que tanto podem se cruzar como se apresentar antagônicas. "As identidades estão sujeitas a uma historicização radical, estando constantemente em processo de mudança e transformação" (HALL, 2005, p.108). 
A identidade adquire sentido por meio da linguagem, a qual é entendida como discurso, enquanto prática social que envolve os sujeitos em determinadas condições de produção. Todo discurso provém de um sujeito posicionado sócio-historicamente em uma formação discursiva dada, que marca suas posições identitárias e o localiza na vida social no e pelo discurso. Sendo assim, ao enunciar, o sujeito assume diferentes papéis que podem ter maior ou menor relevância de acordo com o contexto enunciativo, embora todos eles sejam parte constituinte de sua identidade.

Sabe-se que o poder de persuasão de um discurso decorre também do fato de que leva o interlocutor a identificar-se com a movimentação de um corpo investido de valores historicamente especificados. A pretensão da análise aqui apresentada é investigar essa identificação e, consequentemente, o ethos e a identidade construída para o bom professor nas páginas da Revista Nova Escola.

\section{A discursivização da revista Nova Escola: ethos e identidade}

Acreditamos que a linguagem não deve ser vista apenas como um sistema de simbolização abstrato, mas sim, como prática integrada à experiência cotidiana dos falantes, situados em uma estrutura social determinada. Dessa forma, nos propomos a abordar um discurso que, simbolicamente, por intermédio da linguagem, posicione o indivíduo no tempo e no espaço de uma dada coletividade. $\mathrm{O}$ que proporciona uma rede de relações entre língua, sujeito e história perpassada pelo viés ideológico, com o desencadeamento de efeitos de sentido específicos. Nessa perspectiva, selecionamos dois artigos publicados entre o período de junho de 2009 e agosto de 2010, na coluna Pense Nisso, da Revista Nova Escola. É interessante refletirmos acerca do título da coluna que propõe/convida o enunciatário a refletir sobre os temas aí ofertados. Esse convite aparece marcado por um verbo no imperativo "pense", o qual não deixa de ser uma ordem direta para o leitor.

Nos dois artigos analisados o enunciador procura apresentar um ponto de vista a partir de uma questão polêmica. No texto "O ato de ensinar e a condição humana", o sujeito procura polemizar ao discorrer acerca da responsabilidade de ensinar e sobre o comportamento que um bom profissional deve seguir. A sequência discursiva abaixo se refere ao primeiro parágrafo do artigo:

A palavra professor vem de "professar", que, além de lecionar, significa 'declarar publicamente uma convicção ou um compromisso de conduta', como a de uma profissão. Não por acaso, as duas têm a mesma raiz. Nós, mestres, somos profissionais em vários sentidos: por ensinarmos e por nos comprometermos com condutas de trabalho, numa atividade que exige a contínua exposição de convicções. Essa condição também envolve responsabilidades múltiplas, com conhecimentos e procedimentos, especialmente por lidarmos com muitos jovens e crianças e por um tempo longo.

O enunciador atrela o papel do professor ao ato de "declarar publicamente uma convicção ou um compromisso de conduta". Observamos que há uma remissão ao interdiscurso presente no imaginário coletivo social que busca atribuir ao docente à função de colaborador na formação do caráter dos alunos por meio de suas convicções. Temos, então, uma ampliação para a posição social de professor, que não se limita ao ato de ensinar e que corrobora com os valores sócio-culturais predominantes na sociedade. $\mathrm{O}$ enunciador em sua discursivização assume o nós inclusivo e também se coloca na mesma condição do

\begin{tabular}{|l|l|l|l|l|l|}
\hline Interfaces da Educ. & Paranaíba & v. 2 & n. 5 & p.24-33 & 2011 \\
\hline
\end{tabular}


enunciatário ao enunciar: "Nós, mestres, somos profissionais". Dessa forma, busca maior proximidade com o leitor e recupera seu papel social de professor para validar e dar autoridade ao seu discurso.

A marca linguística da polêmica, que integra o gênero discursivo artigo, é recorrente no segundo texto intitulado "Será que existe professor (a) ideal?" em que o enunciador expõe o sujeito da educação ao apontar as características que devem permear a prática de um bom professor. Nos enunciados que compõem o primeiro parágrafo textual o sujeito procura instalar a polêmica:

Visitando escolas, encontro casos de excelência no trabalho coletivo de professores, assim como de atuações individuais excepcionais. No entanto, ao dar destaque a eles, tenho sido questionado por alguns leitores sobre eventuais idealizações de minha parte. Segundo eles, os personagens de meus exemplos provavelmente não teriam o mesmo desempenho se encarassem condições adversas, como violência, indisciplina e problemas de infraestrutura ou de ordem material.

O enunciador destaca ações positivas no trabalho docente e traz para sua discursivização outra formação discursiva ao enunciar: "No entanto, ao dar destaque a eles, tenho sido questionado por alguns leitores sobre eventuais idealizações de minha parte". Nessa materialidade discursiva há referência aqueles que acreditam que a boa prática docente só é possível em condições adequadas de trabalho, nas quais não existe violência, indisciplina e problemas de infraestrutura ou de ordem material. Essa formação discursiva é citada para ser refutada na sequência textual, conforme segue abaixo:

Em respeito a essa preocupação, reitero que não falo de professores notáveis, com superpoderes e capazes de qualquer proeza, em qualquer situação. É preferível valorizar o trabalho de profissionais que fazem o possível nas circunstâncias que enfrentam, com os recursos de que dispõem.

Aqui há a reiteração do perfil do professor citado no artigo: "profissionais que fazem o possível nas circunstâncias que enfrentam, com os recursos de que dispõem". O enunciador ao se justificar vincula sua posição ideológica discursiva e busca explicitar que o bom professor é aquele que, independentemente das condições em que atua, sempre procura fazer o melhor.

O sujeito discursivo se vale do recurso lingüístico da comparação em seus textos, conforme podemos observar quando ele coteja o professor e o motorista de ônibus:

Outras profissões também dependem fortemente do discernimento e das condições individuais de quem as exerce. Um motorista de ônibus, por exemplo, mais do que um condutor de toneladas de aço sobre rodas, sabe que curva fechada não combina com noite mal dormida e pode custar vidas.

Apesar da comparação aqui presente, o enunciador destaca que "as responsabilidades de educador" são "ainda mais complexas", portanto, consequentemente atribui maior importância à atividade docente. Essa situação é reforçada por meio do emprego do operador argumentativo "aliás", ao ressaltar que os alunos não são meros passageiros e que não enxergam seu educador como um simples condutor ao destino desejado, conforme é apresentado no trecho a seguir: 
As responsabilidades de educador, ainda mais complexas, são cumpridas em circunstâncias muito especiais, sob permanente exposição a dezenas de olhares daqueles que pretendemos formar. Aliás, os alunos não são passageiros e não nos consideram somente condutores de classes ou especialistas em Ciências ou Arte.

No terceiro parágrafo do artigo "Será que existe professor ideal?" o enunciador menciona a construção argumentativa do texto publicitário, o qual apresenta personagens idealizados no imaginário social para vender mais facilmente um produto:

Idealizações são artificiais, como as imagens tão comuns em propagandas de carro de luxo, que mostram ao volante um jovem atlético, sorridente e ousado, mesmo quando se sabe que a maioria dos proprietários é mais velha, séria e cautelosa. A intenção é facilitar a venda, associando esse virtual comprador ao produto.

E, logo em seguida, refuta essa organização presente no interdiscurso publicitário ao afirmar que as qualidades dos professores "nada têm de publicitárias".

O sujeito do discurso, em seu fazer enunciativo, elenca as qualidades que alguns educadores brasileiros possuem: "lucidez, respeito próprio, comprometimento, consciência do próprio valor, busca ao conhecimento e ao aperfeiçoamento profissional constantemente, solidariedade e coragem". É interessante ressaltarmos que no que diz respeito ao conhecimento e aperfeiçoamento profissional contínuos, há no fio discursivo a referência que os profissionais da educação "não se acomodam com o que já sabem, mas buscam aperfeiçoamento didático e cultural permanente". Essa característica constitui a doxa cristalizada no saber popular, o qual em sua rede de filiações sócio-históricas mobiliza na memória do leitor a necessidade do docente buscar formação e aperfeiçoamento incessantemente, uma vez que esse profissional deve ser "detentor do saber". Assim, busca promover a adesão interlocutiva do enunciatário, por meio daquilo que já está consolidado no senso-comum.

A partir dos atributos elencados anteriormente, o enunciador procura delinear o ethos do professor para o leitor da Revista Nova Escola. E determina para esse profissional uma imagem ancorada em estereótipos, os quais contribuem para conferir maior eficácia argumentativa à discursivização. Nesse processo discursivo, o sujeito busca a construção da identidade do bom professor, a qual é endossada pela revista.

Em outra sequência discursiva: "Além disso, minha seleção é muito variada e inclui gente expansiva e tímida, jovem e madura, comunicativa e reservada, simples ou descolada", o enunciador caracteriza o bom docente por meio dos adjetivos: "tímida, jovem, madura, comunicativa, reservada, simples, descolada". Essas adjetivações são formadas por pares antagônicos que, a partir da ideia de oposição, procuram abranger diferentes comportamentos que os profissionais apresentam e, sendo assim, todos podem ser bons.

A identidade do bom professor é construída nos textos a partir de oposições e o enunciador procura apontar atitudes que não fazem parte dessa identidade:

Num extremo, a ostensiva displicência dos que contaminam o convívio profissional com frustrações e raivas. Noutro, a blindagem dos que se escondem sob máscaras inexpressivas, como se em vida de educador não caibam sentimentos. 
O diferente é citado no discurso para ser negado, uma vez que a "displicência" e a "falta de sensibilidade" não integram o perfil de um bom profissional. Tem-se aqui o jogo de poder na construção da identidade que, por meio da relação com o Outro, da relação com aquilo que o professor não deve ser, delineia-se seu exterior constitutivo. A identidade se forma por meio da diferença em uma produção simbólica e discursiva.

Para convencer o leitor da veracidade da identidade construída para o bom docente o enunciador interpela ideologicamente o enunciatário por meio do pronome "você" na tentativa de simular um diálogo, uma conversa com o leitor:

Você sabe que não se fazem estátuas de educadores assim, mas eles podem ser encontrados ensinando em qualquer escola, na sua, inclusive. E, quem sabe, usando seus sapatos.

Ao empregar os dêiticos pessoais "sua" e "seus" o sujeito procura sugerir ao leitor que ele também pode ser um professor ideal (conforme a indagação formulada no título). E encerra o texto usando a metonímia ao afirmar que, esse professor pode usar "seus sapatos". Ao fazer essa comparação reitera que o educador exemplar e bem sucedido pode ser o próprio enunciatário.

A partir de sua formação discursiva o enunciador no trecho do texto: "O ato de ensinar e a condição humana", apresentado abaixo:

No corpo docente de uma escola, há diferentes gêneros, preferências, estilos e situações de vida, mas nem todo comportamento é compatível com a função docente, pois a arte-ciência da profissão exige convívio, com respeito à condição dos outros (e também à própria) e o reconhecimento dos limites nessa recíproca exposição.

Admite no primeiro enunciado que em uma escola existem diversos professores, com diferentes posições, opiniões e até questões pessoais, reconhecendo a validade dos argumentos contidos nessa construção sintagmática. Entretanto, emprega o operador argumentativo "mas" para acrescentar um segundo enunciado - "mas nem todo comportamento é compatível com a função docente" - como um argumento mais forte que leva a conclusão contrária á sugerida no primeiro enunciado. Esse procedimento do sujeito discursivo, ao admitir os argumentos que serão refutados, colabora para tornar mais sólida e convincente a argumentação no sentido oposto, o que leva o leitor a aceitação da veracidade do fato veiculado. Para endossar e enfatizar a conclusão apresentada no enunciado anterior composto por "mas", usa no enunciado seguinte a conjunção coordenativa explicativa "pois". O verbo "exige" conjugado no presente do indicativo exprime a certeza do sujeito ao enunciar que para ser professor deve-se respeitar a condição alheia e até de si mesmo de acordo com o convívio entre os educadores. Podemos concluir que uma das características de um bom docente é o respeito pela própria condição e pelas pessoas que o cercam. Nesse texto observamos que o conceito de respeito abrange um escopo mais amplo do que aquele sugerido no artigo: “Será que existe professor (a) ideal?” já apresentado anteriormente.

$\mathrm{O}$ autoconhecimento e o conhecimento das necessidades dos alunos são atributos apontados pelo enunciador como necessários ao profissional docente, quando afirma que: "Os meninos e as meninas que educamos constituem uma enorme diversidade e só percebendo nossa condição ficamos atentos à deles também". Ao introduzir o operador argumentativo "no entanto" estabelece uma relação argumentativa entre a sequência sintagmática anterior e a 
seguinte ao concluir que: "no entanto, não se sustenta sem uma clara determinação para promover a aprendizagem, com boas exposições e a participação dos alunos nas aulas". Aqui, é interessante sublinharmos que apesar do professor ter autoconhecimento e conhecer seus alunos o que necessita prevalecer é a promoção da aprendizagem, uma vez que essa é a função peculiar ao papel social do educador. E, segundo o enunciador, se o professor realmente proporcionar a aprendizagem dos alunos ele "assegura o respeito" as suas fragilidades e conquista "a admiração" dos seus educandos.

\section{Considerações Finais}

A história se faz presente na língua e toda palavra se origina de um discurso que reflete efeitos de sentidos de acordo com o contexto de produção, a formação discursiva e ideológica que dispõe a discursivização. O corpus analisado procura definir a imagem do bom professor e para conferir maior eficácia argumentativa à discursivização o enunciador utiliza a linguagem coloquial, a polêmica, a comparação e a refutação. Ao construir a doxa do docente, o enunciador lhe atribui os seguintes valores: lucidez, respeito próprio, comprometimento, consciência do próprio valor, busca ao conhecimento e ao aperfeiçoamento profissional constantemente, solidariedade e coragem. É interessante ressaltar que o sujeito tenta definir o ethos do professor para o leitor da revista ao ancorar sua imagem a estereótipos já consolidados no imaginário social. A partir daí, o periódico endossa a identidade do bom professor. Além disso, ao construir essa identidade toma por base a diferença, atitudes que não condizem com a imagem do bom professor são citadas para mostrar aquilo que o docente não deve ser. Dessa forma, por meio da relação com o Outro, com o diferente forma-se o exterior constitutivo daquele considerado bom profissional.

\section{Referências Bibliográficas}

AMOSSY, Ruth (org.). Imagens de si no discurso: a construção do ethos. São Paulo: Contexto, 2005.

COURTINE, J. J. "Définition d'Orientations Théoriques et Méthodologiques en Analyse de Discours. Philosophiques, vol. IX n.2, Paris: 1984.

HALL, Stuart. Quem precisa da identidade?. In: SILVA, T. T. (Org.) Identidade e diferença: a perspectiva dos estudos culturais. 4. ed. Petrópolis: Vozes, 2005. p. 103-133.

NOVA ESCOLA, revista. A tecnologia que ajuda a ensinar. Edição de junho/julho 2009. In: MENEZES, Luís Carlos de. Pense nisso: O ato de ensinar e a condição humana. p. 114.

MENEZES, Luís Carlos de. Pense nisso: Será que existe professor ideal?. Nova Escola. Ler na escola. Edição ago. 2010. p. 106.

ORLANDI, Eni. Interpretação: Discurso e Leitura. Rio de Janeiro: Vozes, 1996.

PÊCHEUX, M. O discurso: estrutura ou acontecimento. Campinas: Pontes, 1990.

Semântica e discurso: uma crítica à afirmação do óbvio. Campinas: Ed. da

Unicamp, 1997.

PÊCHEUX. M. Les Vérités de la Palice. Paris: Maspero, 1975.

WOODWARD, Kathryn. Identidade e diferença: uma introdução teórica e conceitual. In: SILVA, T. T. (Org.). Identidade e diferença: a perspectiva dos estudos culturais. $4^{\mathrm{a}}$ ed. Petrópolis: Vozes, 2005. p. 7-72. 